\title{
Strategies for Teaching Academic Writing to Saudi L2 Learners
}

\author{
Syed Sarwar Hussain ${ }^{1}$ \\ ${ }^{1}$ Department of Linguistics and Translation Studies, College of Languages and Translation, King Saud \\ University, KSA \\ Correspondence: Syed Sarwar Hussain, Department of Linguistics and Translation Studies, College of \\ Languages and Translation, King Saud University, KSA.
}

Received: August 20, 2019 Accepted: November 1, 2019 Online Published: November 3, 2019

doi: 10.5539/elt.v12n12p1 URL: https://doi.org/10.5539/elt.v12n12p1

\begin{abstract}
Of all English Language skills, writing poses the greatest challenge for students due to the demands of style, structure and vocabulary. Even if second language learners (L2 learners) can speak the language well enough for everyday activities - shopping, traveling, and so on, producing an academic write-up that is precise, accurate, objective and fully referenced is still quite a task. This study aimed to determine the academic writing strategies used in ESP classrooms. Along with this, the study determined the perceived proficiency of L2 learners in academic writing, based on their ESP test course. The study also reports the needs of L2 learners in academic writing, and how English for Academic Purposes (EAP) instructors can help to improve the writing skills of L2 learners. The study participants consisted of $60 \mathrm{~L} 2$ learners from various departments in King Saud University. A questionnaire was used to gather the responses of participants. The data was analyzed using SPSS 20.0 software. The results are displayed in descriptive statistics - frequencies and percentages. Inferences were made from the quantitative data, which formed the bases of discussion of the results of the study. The study found that L2 learners consider their academic writing skills to be adequate. This was reported as perceived proficiency since previous studies have reported discrepancies between the perception of teachers and students. L2 learners also revealed that they need to improve on grammar, vocabulary and punctuation as well as the use of academic writing strategies. The study revealed that majority of the respondents use strategies such as outlining and brainstorming. L2 learners performed above average when they use these writing strategies. However, L2 learners want EAP instructors to improve on core ESP topics including grammar, vocabulary and the use of writing strategies. Still, others want EAP instructors to improve on their teaching methods, as well as create an all-inclusive environment for students.
\end{abstract}

Keywords: academic writing skills, EAP, language acquisition, L2 learners, writing strategies

\section{Introduction}

Children acquire their first language by listening. This acquisition of language is relatively easy since it is their mothers' tongue or native language. They learn to understand language based on context. A two-year-old understands actions to be synonymous with certain words they hear - eat, sleep, drink, and so on. The same context is followed when they begin to understand language in a deeper context. Similarly, young first language (L1) learners become familiar with manners and norms of the society and develop deeper insights into the use of idioms and proverbs. It is relatively an easy process. Here, the first language (L1) is acquired.

The same level of ease is not associated with language learning for second language (L2) learners (McCaul, 2016). L2 learners have to go through a series of stages to use their language of choice successfully.

- The silent stage: While many researchers believe the silent stage is essentially a stage of comprehension (Ellis, 1994), others believe it has its own role to play in language learning (Krashen, 1982). First, like young L1 learners, L2 learners listen to their desired L2 language being spoken. They listen without attempting to speak. While listening, they pick up words that would form the crux of their early vocabulary or speech.

- The formulaic stage: Proceeding from the silent stage, many language learners are urged to speak, even if they produce incorrect sentences. Failure is good for success. At this stage, the L2 learner begins to speak, only a few words at a time. This stage has a unique pattern of its own:

- The L2 learner only utters a few words at a time;

$\circ \quad$ And this is done occasionally. 
○ Utterances could be previously memorized as in the case of greetings: "Good morning”, "Good afternoon”, "How are you?" and so on.

○ These few words could also be partially memorized utterances: "May I have a ". They learn to use this often enough and fill out the gap with the appropriate words.

- Input stage: At the input stage, the L2 learner has advanced to become a speaker of the language, albeit not fluently. A characteristic of this stage however, is that the L2 speaker still lacks confidence. The L2 speaker also needs to develop more vocabulary in order to use the language maximally. Here, the speaker also appreciates feedbacks and learns to put it into use in future. Behaviorists believe that this feedback transitions the L2 speaker into a full language-user.

- The Output Stage: The speaker has gone past the anxiety stage. He now speaks the language successfully with some level of confidence. Coming through the previous stages to get to this stage might have taken months or even years to get through. A language learner does not relent. However, he continues to pick up vocabulary and use the language at every opportunity he gets. Vocabulary forms the crux of language learning for L2 learners.

The order of language acquisition does not follow a uniform pattern (Edmondson, 1999). They are influenced by different phenomena:

- Frequency of contact with particular utterances: An L2 learner acquires peculiar vocabulary depending on what they are exposed to. While such phrases as "Good morning", "How are you are?" are used universally, the setting in which a learner finds himself determines the secondary vocabulary he acquires. A student in an academic setting will be exposed to vocabularies in his field of study. With time, he would learn to use these set of vocabularies before acquiring vocabularies that are not related to his field of study. This is the same for a new doctor in a different country.

- Frequency of use: With failure comes success. Learners have to actually make effort. A language is not acquired by only listening, but by attempting to speak and using feedback positively. It is a 'use it' or 'lose-it' technique. Language learning ability correlates positively with frequency of language usage (Gollan et al., 2016).

\subsection{Learning English Language for Academic Purposes}

English for Academic purposes is essentially designed for tertiary-level institute language learners. It is assumed that this category of students have acquired English language from previous English for General Purposes (EGP) classrooms at lower education levels. English for Academic Purposes seeks to assist learners with such skills as reading and listening comprehension, developing proficiency, developing oral language skills, and grammar and writing. Other non-soft skills that EAP assists students with include: note taking in classroom, test taking, using vocabulary related to their field of learning, critical thinking to produce suitable text, research and library skills, reading and comprehending studies - lecture notes, textbook, journal paper, and other research works in their field of study.

Of all English Language skills, writing poses the greatest challenge for academic learners due to the demands of style, structure and vocabulary. Even if students can speak the language well enough for everyday activities shopping, traveling, and so on, producing an academic written work that is precise, accurate, objective and fully referenced is still quite a task. Formal vocabulary is different from everyday speech. It is clearly different from the structure of novels and newspapers. Students perceive writing to be difficult because academic writing has no specific structure. It varies depending on the task. Punctuation is also an issue since the full stop, reversed comma and reversed question mark are the only well-known punctuation in Arabic (Gomez, 2018). Lack of the use of punctuation means academic texts remain unclear. As important as academic writing is to the success of an academic pursuit, it is the English Language skill that poses the most threat to L2 learners (Barkaoui, 2007; Daud et al., 2016; Hussain, 2017).

\subsection{Academic Writing for L2 Learners}

Academic writing has no real structure, it is a wide spectrum (Li, 2007). The writing success of an L2 learner depends on his ability to identify the requirements of a task. The complex nature of academic writing makes it seemingly difficult for students to succeed at writing. Many L2 learners are also not familiar with the writing strategies required for each writing task. Students are often required to write the following:

- Notes;

- Essay;

- $\quad$ Term paper; 
- $\quad$ Research paper;

- Undergraduate project report;

- Master's thesis; and so on.

If L2 learners can identify each of these and their required style of writing, they would have taken one step towards achieving their writing goal.

- Essays: Academic essays are basically a presentation of the writer's idea. It is short in length with an average of 5 paragraphs. Essays in classrooms are assigned for amateur writing practice. L2 writers learn to hone their writing skills by presenting ideas in a thoughtful and logical manner. This writing type incorporates a literature review. A literature review is an evaluation of the information that has been read on a topic. The L2 learner is expected to use such strategies as summarization, evaluation, description and clarification. There are no specified blocks of or sub-headings, the writer categorizes the write-up as he deems fit.

- Term paper: A go-between essay and research paper, writing a term paper essentially prepares an L2 learner for writing a full-term research paper. A term paper signifies a topic or more that has been comprehended by an L2 learner. It is expected that the paper criticizes current topics and allows for the writer's opinions, with facts from a variety of reliable sources. A rule of thumb is that a term paper should have between $1-3$ references per page. Technically, a research paper answers theoretical questions posed by the writer.

- $\quad$ Research paper: The real difference between a research paper and a term paper is that an academic study is carried out. A research paper is the culmination of a researchers' work on a particular topic. The research paper also expresses a writer's idea as well as incorporate the ideas and insights of others. It is at least 8 pages in length. The researcher is expected to familiarize himself with other papers previously written on the topic of interest. The writer can choose to write on a subject scenario, in which case it is called a 'case study'. The writer is expected to restructure and present the topic while incorporating citation to support the analysis (Moreno, 2011).

- Dissertation/Thesis: A dissertation is more like an academic book. It is required to be submitted in partial fulfillment of the requirement of an academic degree. An L2 academic write-ups are also based on a hypothesis. The writer presents hypothetical questions and solves this along the body of the dissertation or thesis.

A similarity among all three (research paper, dissertation and thesis) is that they are structured out into:

\section{- Introduction}

- Literature Review

- Research Methodology

- Results

- Discussion

- Conclusion

Since dissertations and theses have a larger body of text, they are further categorized into the under-listed sub-headings to ensure clarity.

- Introduction

- Background of the study

○ Problem statement

- Objective

- Literature Review

- Methodology

- Research design

- Data analysis

- Results

- Discussion

- Conclusion

- Recommendation

As straightforward as this could be, English for Academic Purposes (EAP) instructors need to assist learners with 
understanding each writing task, only then can L2 learners be able to prepare appropriately for each writing task.

\subsection{Research Questions}

1) What percentage of $L 2$ learners use academic writing strategies?

2) Does the use of pre-writing strategies improve the performance of L2 learner in academic essays?

3) How do L2 learners at King Saud University perceive their own proficiency in academic writing?

4) What is the perceived need of $L 2$ learners in academic writing?

5) How can EAP instructors help to improve the proficiency of L2 learners in academic writing?

\section{Literature Review}

\subsection{Strategies for Teaching Academic Writing to L2 Learners}

While L2 learners have had long-term English Language training for years, the complex nature of academic writing still makes it difficult for many to grasp (Munoz-Luna, 2015). By developing an active use of academic writing strategies, L2 learners can master academic writing skills. It is the role of English for Academic Purposes (EAP) instructors to ensure the curriculum is presented in a way that makes it easy for L2 learners to develop proficiency in academic writing.

\subsection{Rhetorical Strategies for Academic Writing}

Students can employ a variety of methods in order to make their writing compelling. This section outlines some of the methods often employed by expert writers. L2 learners can use a combination of these strategies depending on the writing task. To use these strategies successfully, L2 learners are expected to connect facts in a sequence. A written piece should be a cluster of important information which conveys the purpose of an argument (Williams, 1999). The following rhetorical strategies can help L2 learners paint a vivid picture from their writing:

- Definition: No essay is complete without a definition. The main parts of an essay topic has to be clearly defined before supporting ideas are added. An L2 writer should provide the meaning of terms before they are further buttressed in the body of work. Definitions should be based on context. New vocabularies should be defined to avoid ambiguity.

- Exemplification: When employing the exemplification strategy, L2 learners should learn to use specific, vivid examples. These examples can be fortified by illustrating a general idea that is relevant to readers. Excellent examples are always related to the topic. Depending on the length of writing required, writers may use only one example, or several examples. Any facts or statistics that are used as examples need to be accurate. The details should be specific enough to accomplish clarity of the idea set forth in the topic sentence.

- Description: As a writing strategy, description involves showing rather than telling. A writer should help readers get a clear view of what he is writing about. Definitions are not enough. It is important to make the subject of the discussion come alive. When describing, a writer should ensure appropriate word usage - noun, verbs, and adjectives that paints his ideas in bright colors, vivid and specific. In scientific lab reports, the writer needs to put down the details of what he sees, smells and perceives.

- Narration: When narrating an experience, an L2 writer should think about sequence - a chronological order, or an order which an event might be most dramatically related. The writer must also consider incorporating time markers for audience clarity. For instance,

"Following the removal of the cast, the engineers removed the excess materials formed as a result of the casting process."

'Following the removal' here, is the time marker. Writing a report without time markers makes it difficult for an audience to understand or follow the sequence of an event. Other time markers include 'first', 'meanwhile', 'later', 'afterwards', and so on.

- Process Analysis: To use this strategy, an L2 writer needs to explain the process an event goes through. This could be an experiment, or it could be a fieldwork. In writing a report, the writer presents the project summary. It is important to explain the procedures using specific keywords. It might be necessary sometimes to be historical about the process analysis. The procedures of a process or an experiment in recent times might not be the same as some years or even months ago. It would give the reader better clarity if both processes are related in the piece of write-up. Essentially, the writer should assist the reader in exploring the meaning and purpose of each step of the process. Like narration, sequence is crucial to a process analysis. If required, for clarity, a writer is expected to make a list, a flowchart, or even use graphics where appropriate. 
- Comparison and Contrast: Comparison looks for the difference in similar things. To describe how a process or an item is different from another, an L2 writer needs to consider the similarities and differences. That is, compare and contrast. There are two strategies for using the compare and contrast strategy:

- The paragraph approach: The writer may state a similarity that connects both items and processes, and then state why the methods or systems are different within the same paragraph. This is done for every paragraph necessary within the write-up.

- Or, the writer can choose to list the similarities first, buttressing individual points with each paragraph. Next, the writer lists the contrasts, buttressing each point in paragraphs. The writer lists both similarities and contrasts by order of significance. He rounds up with a concluding paragraph stating the basic points that make the two methods, processes or items different.

Using the compare and contrast strategy is an excellent approach for writing a report, making an argument in an Op-Ed, or giving a speech to persuade an audience to take a specific course of action.

\subsubsection{Pre-Writing Strategy: Outlining}

Before setting a pen to paper, an L2 writer should have thought out the appropriate strategy for the task. An L2 writer needs to make an outline before writing full-length paragraphs in order not to lose focus. A first rule of thumb that EAP instructors need to make mandatory for L2 learners is: designing an outline before commencing on the writing assignment. This makes a huge difference in the academic genre, both in text preparation and composition. It helps L2 learners achieve better organization in their piece of write-up.

\subsection{Writing Paragraphs}

L2 learners should always start a paragraph with a topic sentence. The topic sentence is the most important part of the paragraph; it is what the paragraph is about. For a term paper on 'Water Management' for instance, an introduction could look like this:

"While water is a renewable resource, supply is limited when demand is increasing; hence, management of existing water sources is required."

Here, the writer has introduced his main point in the topic sentence. Ideally, supporting sentences should be introduced after the topic sentence. This would make up about three to six sentences. These supporting sentences could be RENNS - Reasons, examples, names, numbers, senses. These give details and explain the topic sentence. One or two concluding sentences succinctly summarizes the supporting sentences. Sometimes, it also opens ground for the next paragraph, linking one paragraph to the next. So, a paragraph could look like this:

"While water is a renewable resource, supply is limited when demand is increasing; hence, management of existing water sources is required. Water has many uses. It is important in agriculture, industry, recreation, and for consumption. Land-based life on Earth revolves around water. Domesticated plants require a regular and sufficient supply of sweet water. With world population growing by 1.6 percent a year, it is predicted that by 2025 , about 52 countries will experience water scarcity. People must manage this water resource; they must also manage the supply of sweet water for humans, for domesticated animals, and for manufacturing."

\subsection{Levels of L2 Writers}

L2 writers can be divided into levels based on their proficiency in writing. Each level of L2 writer exhibit peculiar characteristics. When EAP instructors understand these characteristics, they can further help L2 learners hone their writing skills.

- Surface writers: These levels of writers have not learned to implement the use of strategies in their write-up. They write without first creating an outline. They write as ideas pop into their heads. Overall, the writing focuses on word usage and sentence structure. One sentence does not necessarily link to the other, neither do the paragraphs. The overall write-up is poor and not properly tied together.

- Deep writers: As opposed to surface writers, deep strategizers plan their write-up before they put their pen to paper. They make an outline and have a clear idea for the structure of their proposed write-up (Martin \& Leon, 2014). They focus on organization and structure, using sentence structure and word usage to achieve their aim. Overall, the write-up is well-tied together and portrays a clear point.

It is the role of EAP instructors to help surface writers understand why their write-ups are still lacking in clarity and improve therefrom. Better L2 writers write with a specific purpose, describing, explaining, giving examples and countering claims as they write. Research has found that L2 writers writing for academic purposes make less grammatical mistakes compared to text structure errors (Sayeed, 2016; Chowdhury, 2015). Hence, it is more 
important that L2 writers make use of rhetorical strategies when writing. L2 writers who are aware of rhetorical strategies of writing and actively use them prove to present better write-ups (Munoz-Luna, 2015). Better L2 writers write complex sentences linking verbs, nouns and phrases with prepositions. Two or more facts are related within a single sentence. Weaker writers write short sentences, mostly without relating sentences to each other within a paragraph. Better L2 writers have a more relaxed attitude toward writing. They select words in relation to context. They have a set plan for proofreading. They also have a wide variety of academic vocabulary and resources at their disposal. EAP instructors can determine the writing level of an L2 learner by checking for linguistic accuracy, creativity and originality of ideas. With these, EAP instructors will be able to help L2 learners recognize their mistakes and learn how to avoid them.

\subsection{Miscellaneous Academic Writing Tips}

EAP instructors can also assist L2 learners by introducing the following tips:

- Get L2 learners familiarized with academic journals in their field.

- Have L2 learners note the tense to be used for each writing task and help them understand the exceptional cases.

- Instruct students on references and bibliography as a topic on its own.

- Advice L2 learners to write to specificity. Accuracy is essential. The metal was heated to " $65^{\circ} \mathrm{C}$ " is more accurate than "the metal was very hot."

- It is essential to use an impersonal writing style. The use of I/We should be avoided in academic writing, unless its use is unavoidably important.

- An academic write-up should essentially answer questions that the writer poses. It should "bite itself in the tail".

- The recency of sources is important. It should contribute to modern research and knowledge. It is preferable if it confirms current ideas, or tests or postulates new ideas that might emerge.

- It should not only document the ideas of others; it should also document what the author has learned in his line of work.

- An academic write-up must be objective. It should be based on fact beyond the author's perceptions. The focus is not on the author, but on the paper.

- Avoid abbreviations and slangs.

- Write out units of measurement in full, unless it is widely known.

- For sentences, avoid run-on and fragments

- Run-on sentences: Run-on sentences are fused sentences. A run-on sentence is made of two or more sentence without the proper punctuations.

- Fragments: A sentence fragment is an incomplete sentence. It is a sentence that cannot stand on its own.

- A write-up submitted in haste is no use. L2 learners should learn to proofread their write-up before submission, paying special attention to grammar and spelling.

- Suggest a writer's checklist to L2 learners to help them check their write-up before submission.

Once students become accustomed to the consistent use of these varying methods, it would not be something they have to cram or memorize but rather something that flows freely when they write.

\section{Methodology}

\subsection{Participants}

The study participants consisted of L2 learners in various departments in King Saud University. Participants were asked about the problems they encounter in EAP courses. More specifically, the researcher inquired about the proficiency of participants in academic writing.

\subsection{Sample}

The study sample consisted of 60 students from varying departments at King Saud University. Students were selected from different colleges in the university, including sciences; humanities; health; engineering; food and agricultural sciences; and computer and information science. The students were selected based on a random sampling method. The selection process ensured that the selected students were from varying nationalities, 
including Saudi Arabia, Pakistan, Indonesia, Bangladesh, Nigeria, and so on.

\subsection{Instrument and Data Collection}

Data collected through the use of a questionnaire tried to gauge the usefulness of the techniques used in EAP classrooms. The questionnaire also inquired about the proficiency of L2 learners in academic writing. Other questions explored the needs of $\mathrm{L} 2$ learners in academic writing.

\subsection{Data Analysis}

Responses were analyzed using SPSS 20.0. The results are displayed in descriptive statistics. The quantitative values are represented in frequencies and percentages. Further inferences were drawn from the open-ended questions. The verbal responses of respondents are recorded. These responses formed the basis of the qualitative data. Useful deductions were made from the responses of the study sample.

\section{Results and Findings}

The respondents for this study were from varying nationalities including, Saudi Arabia, India, Pakistan, Nigeria, and so on. Figure 1 presents the data on the field of study of L2 learners. The respondents for this study were enrolled in the following departments in the University: Civil Engineering, Mechanical Engineering, Electrical Engineering, Chemical Engineering, Computer and Information Science, Botany and Microbiology, Mathematics, Medicine, Food Science and Nutrition, Zoology, Petroleum and Natural Gas Engineering, Industrial Engineering, and Biochemistry. Equal percentages $(9.1 \%)$ were recorded for all the departments.

\section{The Percentage of L2 Learners in Various}

\section{Departments}

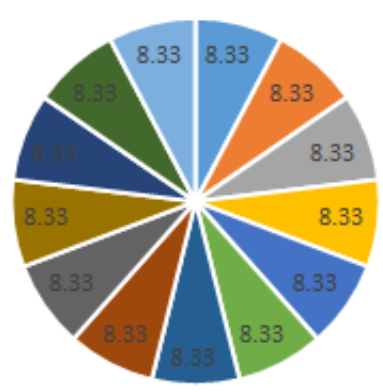

Figure 1. The percentage of L2 learners in various departments

Figure 2 shows that majority of the L2 learners 56(93\%) use academic writing strategies. L2 learners also revealed that they specifically use the following writing strategies: speed-writing - 30(50\%), brainstorming - 30(50\%) and outlining - 40(68\%) (Figure 3). Whether these techniques prove to be useful are indicated by the responses of students concerning their performance when they use academic writing strategies. On a scale of $1-5$ (from very poor to very good), Figure 4 shows the responses of participants. Forty (67\%) L2 learners reported that they perform well (Good) in their essays when they use writing strategies. Twelve $(20 \%)$ reported that they scored average marks. Only $8(13 \%)$ performed below average. These results show that majority, $52(87 \%)$ of L2 learners find these strategies to be relevant in academic writing. This corroborates the finding of Hung \& Van (2018) who found the use of pre-writing strategies - outlining and brainstorming to be useful in organization of ideas. They reported that both strategies help to strengthen the generation of ideas, organization and flow (fluency) of written essays. 


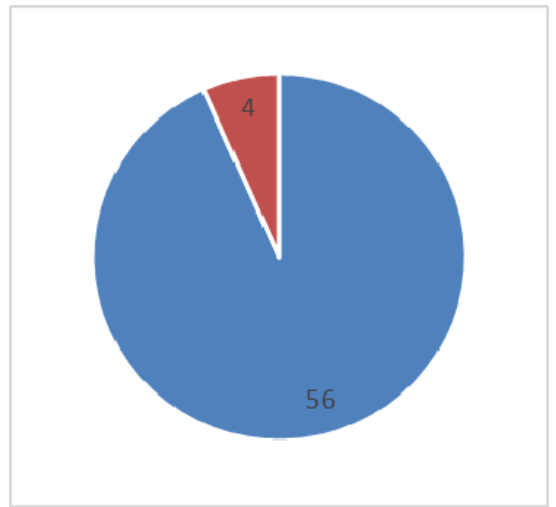

Figure 2. Percentage of L2 learners who use academic writing strategies

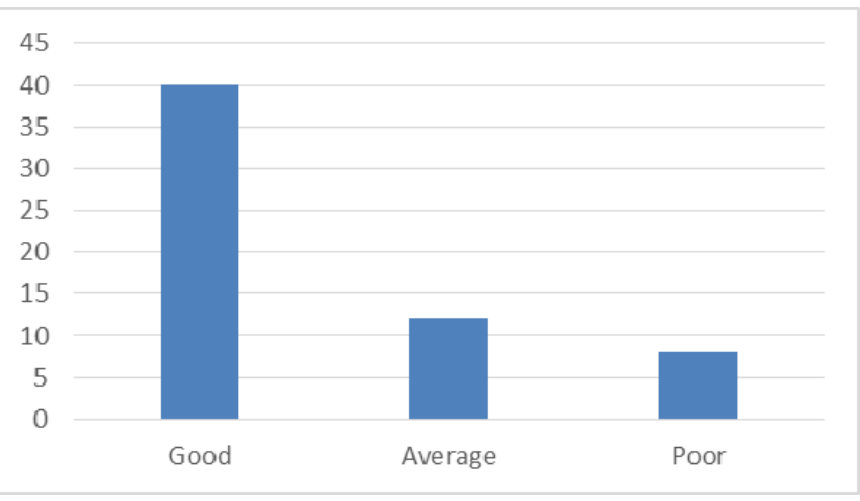

Figure 4. Performance of students when they use writing strategies

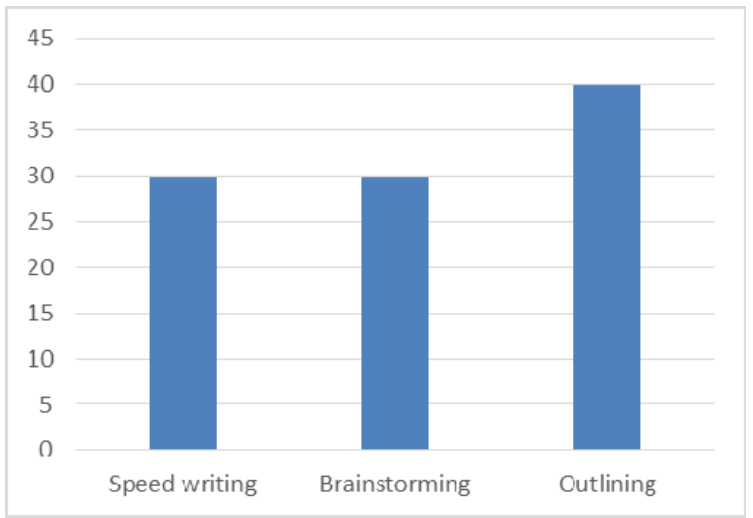

Figure 3. Writing strategies used by L2 learners

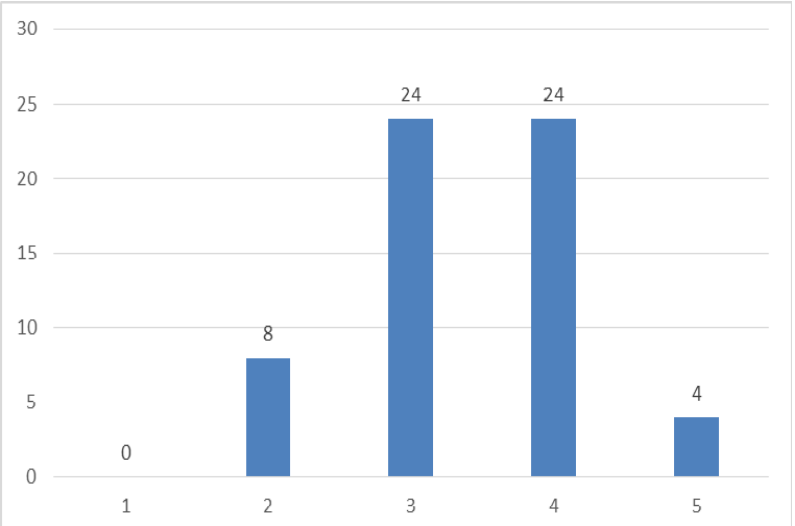

Figure 5. Perceived proficiency of L2 learners in academic writing

Figure 5 shows the performance of L2 learners in academic writing, on a scale of 1 - 5 (corresponding to: very poor to very good), most L2 learners chose the items labeled ' 3 ' - $24(40 \%)$ and ' 4 ' $-24(40 \%)$ on the linear scale. That is, the highest percentage of respondents $(80 \%)$ consider their proficiency in academic writing to be adquate. This was based on their average grade in ESP courses. Eight of them (13.3\%) chose the item ' 2 ' ' on the scale. That is, they consider their academic writing proficiency to be poor. Still, $4(6.7 \%)$ chose ' 5 ', they believe they have excellent academic writing skills. Although majority of the respondents believe that their academic writing skills were either adequate or excellent, it was recorded as perceived proficiency. Long-term studies have found discrepancies in students and instructors' perception of ESP proficiency. In a study conducted by Theoarajah (2012), he reported that students regarded their ESP proficiency to be good, or at least satisfactory. Many believed that they were proficient in English Language. On the contrary, lecturers felt that the proficiency of some of the students was inadequate. The lecturers believed that their students needed further English Language skills, especially reading and writing (Theoarajah, 2012).

When asked what they need academic writing for, L2 learners highlighted 'Grammar', 'Vocabulary', 'Writing style', 'Paragraph and structure' and 'Organization of ideas'. The following are some of the responses of participants:

"My vocabulary is not developed enough and so I wait till I could get a synonym or a close word or expression that can, in a way, express my thoughts."

"They should focus more on grammer".

That is "grammer" in place of "grammar" as written by the respondent. This shows that an improvement is indeed required. As displayed in Figure 6, forty-nine (82\%) of the students responded that they need ESP skills in order to plan and write well-developed arguments in their essays. Forty $(68 \%)$ responded that they need academic writing skills in order to use proper academic conventions (acronyms, citation, references, formal tone of language) appropriately. Fifteen (25\%) were also concerned about the appropriate use of punctuation and vocabulary. This 
corroborates the findings of Akbari (2011), along with emphasizing that instructors should be aware of appropriate learning strategies and styles, he listed grammar, vocabulary, academic knowledge and organization of ideas as the needs of $\mathrm{L} 2$ learners in academic writing.

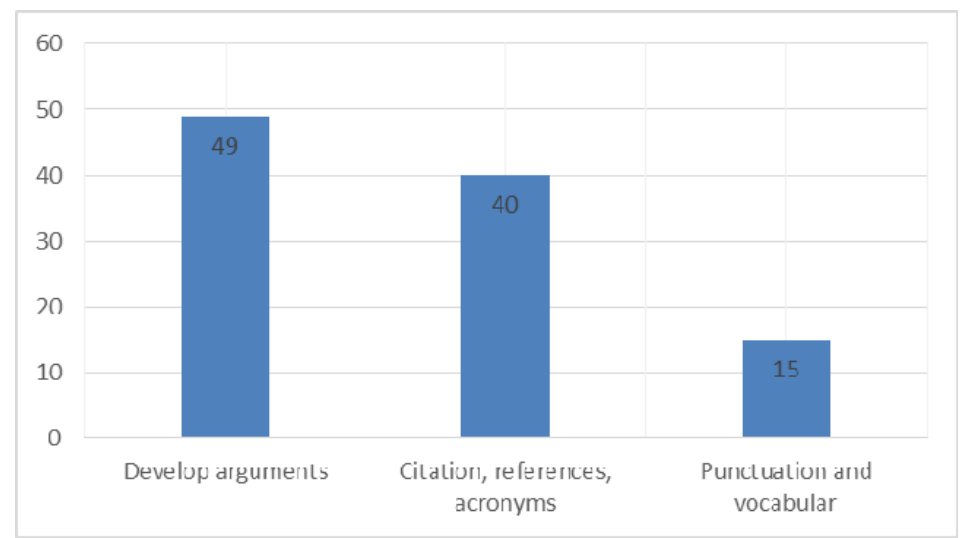

Figure 6. Perceived needs of L2 learners students in academic writing

Regarding how EAP instructors can assist L2 learners in academic writing, Figure 7 shows that respondents want ESP instructors to focus on teaching grammar - 20(33\%) and writing strategies, such as outlining - 10(16.7\%). Some, $15(25 \%)$ want EAP instructors to focus on learning styles and improve on the presentation of topics. Others, $10(16.7 \%)$ expect EAP instructors to concentrate on the class at large, "not just the best students in the class.". Akbari (2012) also noted that apart from teaching the concepts of grammar, vocabulary and general English Language skills, EAP instructors need to create an inclusive learning environment for all students and improve on teaching styles. This would maximize the learning ability of students and improve students' confidence in their own ability to learn the required academic writing skills.

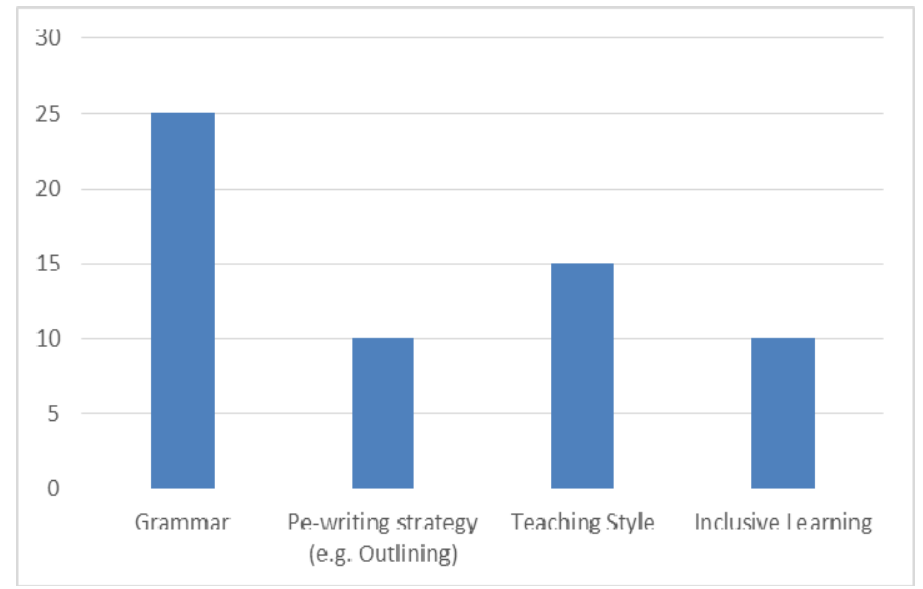

Figure 7. How EAP instructors can improve L2 learners' proficiency

\section{Conclusion}

L2 learners in King Saud University perceive their academic writing skills to be proficient in academic writing, although not excellent, as the charts above show. This is based on their average performance in ESP tests. This conclusion was based on the responses of the study participant. The researcher, however, records these responses as the perceived proficiency. Previous studies have found discrepancies between the perception of teachers and students (Theorajah, 2012). The study also found that majority of L2 learners use writing strategies, such as brainstorming, outlining and speed writing. A higher percentage of L2 learners reported that they performed above average when they used these writing strategies. Still, L2 learners have academic writing needs. They want EAP instructors to focus more on grammar, organization of ideas and use of academic writing strategies. Further, EAP 
instructors need to improve on their teaching styles as well as create an inclusive learning environment for students. This study is limited to the opinions of L2 learners. Further studies can gather the opinions of instructors, regarding teaching academic writing to L2 learners.

\section{References}

Akbari, Z. (2011). Vocabulary comprehension and learning in an ESP context: Strategy use and knowledge sources. Asian ESP Journal, 7(2), 5-27.

Barkaoui, K. (2016). What and when second-language learners revise when responding to timed writing tasks on the computer: The roles of task type, second language proficiency, and keyboarding skills. The Modern Language Journal, 100(1), 320-340. https://doi.org/10.1111/modl.12316

Chowdhury, N. S. (2015). Observing Writing Classes to Explore Students'Writing Problems: A Secondary Level Scenario of EFL Class (Unpublished master's thesis). BRAC University, Dhaka, Bangladesh.

Daud, N. S. M., Daud, N. M., \& Kassim, N. L. A. (2016). Second language writing anxiety: cause or effect? Malaysian Journal of ELT Research, 1(1), 19.

Edmondson, W. (1999). Twelve Lectures on Second Language Acquisition: Foreign Language Teaching and Learning Perspectives. Germany: Gunter Narr Verlag Tubingen.

Ellis, R. (1994). The Study of Second Language Acquisition. China: Oxford University Press.

Gollan, T. H., Starr, J. \& Ferreira, V. S. (2016). More than use it or lose it: The number of speakers' effect on heritage language proficiency. Psychon Bull Rev, 22(1), 147-155. https://doi.org/10.3758/s13423-014-0649-7

Gomez, L. (2018). 5 Writing Trouble Spots for ESL Students of Arabic. Retrieved from http://teaching.monster.com/benefits/articles/10068-5-writing-trouble-spots-for-esl-students-of-arabic?print $=$ true

Hung, B. P. \& Van, L. T. (2018). Depicting and outlining as pre-writing strategies: Experimenting results and learners' opinions. International Journal of Instruction, 11(2), 454-464. https://doi.org/10.12973/ iji.2018.11231a

Hussain, S. S. (2017). Teaching writing to second language learners: Bench-marking strategies for classroom. Arab World English Journal (AWEJ), 8(2), 208-227. https://doi.org/10.24093/awej/vol8no2.15

Krashen, S. D. (1982). Principles and Practice in Second Language Acquisition (pp. 10-32). Oxford: Pergamon Press.

Li, Y. L. (2007). Exploring the use of focused freewriting in developing academic writing. Journal of University Teaching \& Learning Practice, 4(1).

Martín, P., \& León Pérez, I. K. (2014). Convincing peers of the value of one's research: A genre analysis of rhetorical promotion in academic texts. English for Specific Purposes, 34(1), 1-13. https://doi.org/ 10.1016/j.esp.2013.09.002

McCaul, R. W. (2016). Can we learn a second language like we learned our first? Retrieved from https://www.britishcouncil.org/voices-magazine/can-we-learn-second-language-we-learned-our-first.

Moreno, A. I. (2011). English for research publication purposes and cross-cultural academic discourse analysis. In J. Ruano, M. Fernández, M. Borham, M. Díaz, S. Bautista, P. Álvarez, \& B. García (Eds.), Current trends in Anglophone studies: Cultural, linguistic and literary research (pp. 53-69). Salamanca: Ediciones Universidad de Salamanca.

Munoz-Luna, R. (2015). Main ingredients for success in L2 academic writing: Outlining, drafting and proofreading. PLoS One, 10(6). https://doi.org/10.1371/journal.pone.0128309

Sayeed, I. (2016). Error Analysis in writing: A Comparative Study of Bangla Medium and English Medium Schools in Dhaka (Unpublished master's thesis). BRAC University, Dhaka, Bangladesh.

Theorajah, T. R. (2012). The English Language needs of aircraft maintenance engineering students at a private college (Unpublished Thesis). University of Malaya, Malaysia.

Williams, I. A. (1999). Results section of medical research articles: Analysis of rhetorical categories for pedagogical purposes. English for Specific Purposes, 18, 347-366. https://doi.org/10.1016/S0889 $-4906(98) 00003-9$ 


\section{Copyrights}

Copyright for this article is retained by the author(s), with first publication rights granted to the journal.

This is an open-access article distributed under the terms and conditions of the Creative Commons Attribution license (http://creativecommons.org/licenses/by/4.0/). 